\title{
Improving the Critical Current Density in Bi-2223 Wires Via a Reduction of the Secondary Phase Content
}

\author{
Y. B. Huang, X. Y. Cai, T. Holesinger, V. A. Maroni, D. Yu, R. Parrella, M. Rupich, E. Hellstrom, M. Teplitsky, \\ K. Venkataraman, A. Otto, and D. Larbalestier
}

\begin{abstract}
Progress in the performance of multifilamentary composite Bi-2223 wire fabricated at American Superconductor is reviewed. Critical current $\left(I_{c}\right)$ performance of $175 \mathrm{~A}$ at $77 \mathrm{~K}$ and self-field and critical current density $\left(J_{c}\right)$ performance of $22.1 \mathrm{kA} / \mathrm{cm}^{2}$ (77 K, $0.1 \mathrm{~T}$ perpendicular to the tape plane) have been measured for short samples of $\mathrm{Bi}-\mathbf{2 2 2 3}$ wire (standard size is $0.21 \times 4.0 \times 100 \mathrm{~mm}$ ). Microstructure analysis by SQUID magnetometry, transmission XRD and TEM shows a large amount of residual 2212 intergrowth remaining in $\mathrm{Bi}-2223$ grains. Residual 2212 intergrowth is seen to correlate with self-field $J_{c}$ at $77 \mathrm{~K}$ across a range of experimental samples, suggesting that higher levels of performance will be achieved by further reducing residual 2212.
\end{abstract}

Index Terms-Bi-2223 tape, critical current density, high temperature superconductor, microstructure analysis.

\section{INTRODUCTION}

$\mathbf{H}$ IGH Temperature Superconductors (HTS) are widely considered for high power applications used by industrial end-users and electric utilities. Prominent application areas include power transmission cables, electric motors, generators, current limiters, and transformers. Bi-2223 wire prepared by the oxide-powder-in-tube method (OPIT) is currently the most advanced HTS manufacturing method for flexible, multifilamentary composite (MFC) wires. Significant advances in HTS technology have been made at American Superconductors (AMSC). Production wires now show an average performance of $130 \mathrm{~A}(77 \mathrm{~K}$, sf, $1 \mu \mathrm{V} / \mathrm{cm})$, which is equivalent to an engineering current density of $15 \mathrm{kA} / \mathrm{cm}^{2}$. These levels of performance reflect an improvement of $10 \%$

in properties over the past year [1]. Experimental work at AMSC is closely coupled with production for introduction of new processes into the manufacturing line. Experimental tapes typically originate from a section of a production tape. A recent paper by Huang et al. [2] indicates short length performance re-

Manuscript received August 5, 2002.

Y. B. Huang, D. Yu, R. Parrella, M. Rupich, M. Teplitsky, and A. Otto are with American Superconductor, Westborough, MA 01581 USA (e-mail yhuang@amsuper.com).

X. Y. Cai, E. Hellstrom, and D. Larbalestier are with the Applied Superconductivity Center, University of Wisconsin-Madison, Madison, WI 53706 USA (e-mail: xcai@facstaff.wisc.edu; larbalestier@engr.wisc.edu).

T. Holesinger is with Los Alamos National Lab, Los Alamos, NM 087545 USA (e-mail: holesinger@lanl.gov).

V. A. Maroni and K. Venkataraman are with Argonne National Lab., Argonne, IL 60439 USA (e-mail: maroni@cmt.anl.gov).

Digital Object Identifier 10.1109/TASC.2003.812067 sults of up to $170 \mathrm{~A}(77 \mathrm{~K}$, sf, $1 \mu \mathrm{V} / \mathrm{cm})$ which is an additional $13 \%$ improvement over the previous best long length result of $150 \mathrm{~A}$.

To increase production capacity and enable a wire price-performance ratio of $\$ 50 / \mathrm{kAm}$, AMSC is currently establishing a new facility dedicated to the manufacture of MFC wire, with an ultimate capacity of $2 \mathrm{Mm} / \mathrm{year}$. Wire performance levels will continue to increase through integrated research and production activities.

This paper reports on recent performance improvements of AMSC Bi-2223 experimental tapes by secondary phase reduction. Microstructure analysis of the high performance wires by several different methods will be presented and discussed.

\section{EXPERIMENTAL DETAIL}

Multifilamentary Bi-2223 composite wires were fabricated using a powder-in-tube technique [3], [4]. Wires referred to as 'experimental' were cut from long lengths of production wire at different stages of the AMSC standard production process. The nominal dimensions of the 55 filament tapes are $0.2 \mathrm{~mm}$ by $4 \mathrm{~mm}$. The final lengths of the experimental tapes were $\sim 10 \mathrm{~cm}$. AMSC's proprietary processing schedules were modified to produce substantial increases in tape performance that could be correlated with microstructural changes within the tapes. Standard four point techniques at self-field and in applied field were used to determine the transport critical current $\left(I_{c}\right)$. Experimental wires were also measured using a SQUID magnetometer. DC magnetization curves were taken as a function of temperature for $1 \mathrm{~cm}$ wire sections using a standard zero field cooled (ZFC) procedure with a background field of $5 \mathrm{G}$ applied along the wire axis. A transmission electron microscope (TEM) operating at $300 \mathrm{kV}$ was used to analyze specimens prepared in cross-section by dimple polishing and ion-milling. Transmission XRD measurements were performed directly on the standard Ag sheathed wire using $25 \mathrm{keV}$ X-rays produced by an insertion device beam-line at a third generation synchrotron- The Advanced Photon Source (APS) at Argonne National Laboratory [5].

\section{RESULTS AND DISCUSSION}

Modifications to the heat treatment schedule have resulted in significant enhancements of the transport performance of MFC wire. The new superconducting performance levels of some experimental and production wires are summarized in Table I. It is 
TABLE I

RECORD AMSC BI-2223 WiRE PERFORMANCE AT $77 \mathrm{~K}$.

\begin{tabular}{lcc}
\hline & $\begin{array}{c}\text { Production } \\
\text { wire }\end{array}$ & $\begin{array}{c}\text { Experimental } \\
\text { wire }\end{array}$ \\
\hline $\mathrm{I}_{\mathrm{c}}(\mathrm{A}$, self field $)$ & 155 & 175 \\
$\mathrm{I}_{\mathrm{c}}(\mathrm{A}, 0.1 \mathrm{~T}, \mathrm{llc})$ & 68.3 & 74.3 \\
$\mathrm{~J}_{\mathrm{e}}\left(\mathrm{A} / \mathrm{cm}^{2}, \mathrm{sf}\right)$ & 18,000 & 20,200 \\
$\mathrm{~J}_{\mathrm{c}}\left(\mathrm{A} / \mathrm{cm}^{2}, \mathrm{sf}\right)$ & 46,200 & 51,800 \\
$\mathrm{~J}_{\mathrm{c}}\left(\mathrm{A} / \mathrm{cm}^{2}, 0.1 \mathrm{~T}\right)$ & 20,300 & 22,100 \\
\hline
\end{tabular}

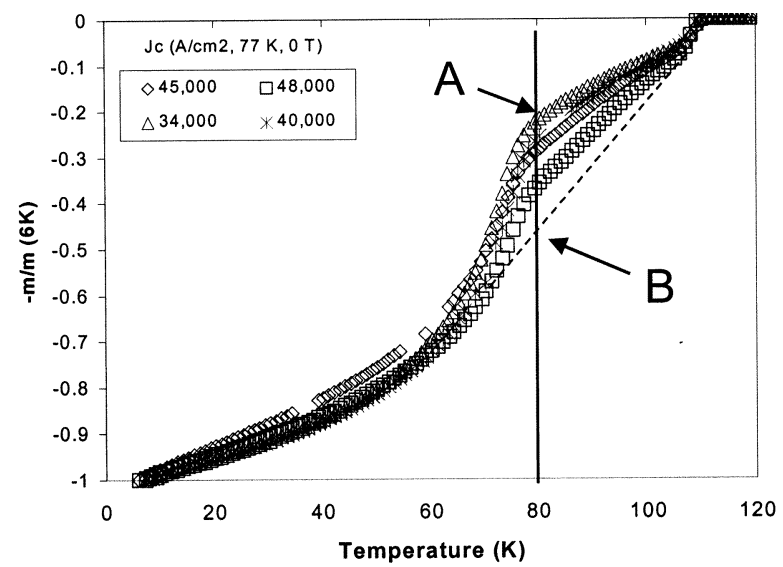

Fig. 1. Normalized DC magnetization of experimental wires with different $J_{c}$ values at $77 \mathrm{~K}$ and self-field. A $30 \%$ rolling reduction before measurement was used to break up grain connectivity.

important to note that the modifications developed to improve short length performance also significantly improved production lengths of MFC wire. These results validate the integrated research and production approach used at AMSC for MFC wire improvements.

Because the self-field significantly suppresses the $I_{c}$ of highcurrent $\mathrm{Bi}-2223$ tapes at $77 \mathrm{~K}$ [6], [7], performance levels are now quantitatively measured in an applied field of $0.1 \mathrm{~T}(/ / \mathrm{c})$ to determine intrinsic material performance. The $J_{c}$ value of $22100 \mathrm{~A} / \mathrm{cm}^{2}$ at $77 \mathrm{~K}$ and $0.1 \mathrm{~T}(/ / \mathrm{c})$ from the new experimental wire reported here is $\sim 10 \%$ higher than the level obtained last year [2], 30\% higher than the estimated $0.1 \mathrm{~T}$ value for AMSC's self-field $J_{c}$ record tape $\left(74 \mathrm{kA} / \mathrm{cm}^{2}, 77 \mathrm{~K}\right.$, made in 1998)[4], and represents a new level of performance for MFC wires.

To better understand the recent improvement and current limiting mechanisms in general, a SQUID characterization method was developed to probe for residual amounts of lower $T_{c} \mathrm{Bi}-2212$ [2]. To reveal the presence of $\mathrm{Bi}-2212$ intergrowth that is normally shielded by the grain connectivity in a fully-processed conductor, wire samples were measured after substantial deformations which break up grain connectivity. The relative amount of Bi-2212 was approximated by measuring the deviation of the magnetization at $80 \mathrm{~K}$ from a straight line drawn between the high-temperature purely 2223 component and the low-temperature magnetization in which all the 2212 and 2223 shields flux, i.e., the value of A-B in Fig. 1. The straight-line approximation is likely to give an underestimation of the deviation due to 2212 . As shown, the normalized magnetization difference at $80 \mathrm{~K}$ decreases as the $J_{c}$ value of

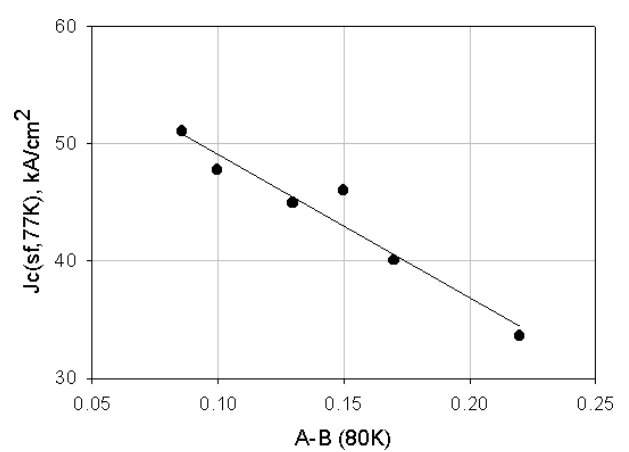

Fig. 2. $J_{c}$ performance plotted as a function of the difference in the magnetization curves of the broken-up experimental tapes and an extrapolated curve for a pure Bi-2223 tape.

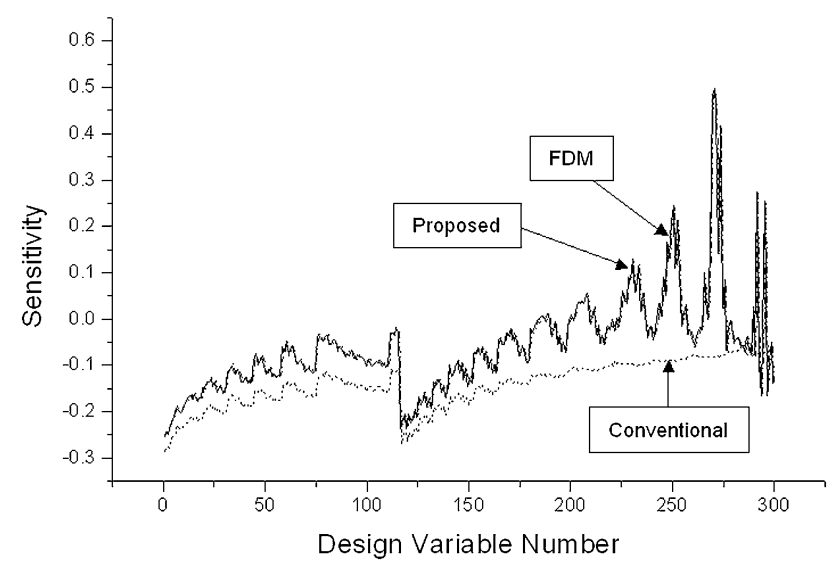

Fig. 3. A portion of the transmission XRD patterns $\left(7^{\circ}<2 \Theta<12^{\circ}\right)$ for two $\mathrm{Ag} / \mathrm{Bi}-2223$ composite wire specimens subjected to alternative heat treatment steps in the final stages of processing: $+=$ the $(115)$ line of $\mathrm{Bi}-2223 ; x=$ $(11 L)$ lines of $\mathrm{Bi}-2212 ;=(H K L)$ lines of the 3221 phase. a) Standard, $J_{c}$ of $40 \mathrm{kA} / \mathrm{cm}^{2}$ and b) Modified, $48 \mathrm{kA} / \mathrm{cm}^{2}(77 \mathrm{~K}, \mathrm{sf})$.

the tape increases. The value of A-B for each tape is plotted as a function of $J_{c}$ value in Fig. 2. Assuming that the A-B value is proportional to the amount of $\mathrm{Bi}-2212, J_{c}$ performance increases as the amount of 2212 decreases, indicating that there is significant potential for further improvement of transport performance by further reducing the amount of 2212 .

Fig. 3 presents through-sample transmission XRD patterns for two samples with $J_{c}(77 \mathrm{~K}, \mathrm{SF})$ of $40 \mathrm{kA} / \mathrm{cm}^{2}$ (by the standard heat treatment) and $48 \mathrm{kA} / \mathrm{cm}^{2}$ (by a modified heat treatment), respectively. The intensities of the 3221 and 2212 lines to the (115) line of 2223 (at $2 \theta=8.38^{\circ}$ ) indicate the lower $J_{c}$ sample contains more 2212 and 3221, which could not readily be identified using the standard XRD method based on a laboratory X-ray source and the use of peeled samples, which are partially penetrated by the X-ray beam [5].

TEM experiments further supported the conclusions from the SQUID and XRD analyzes. The structure of the individual filaments, as seen at the level of TEM, consists of a shell of well-formed $\mathrm{Bi}-2223$ grains next to the silver sheath. This Bi-2223 shell, typically the width of 2 or 3 grains, contains very few intergrowths, thus explaining the very sharp transition of uncrushed wires. Inside this shell, the $\mathrm{Bi}-2223$ grains contain a much higher density of intergrowth of Bi-2212. Large Bi-2212 grains were rare. However, clusters of Bi-2212 layers (typically 


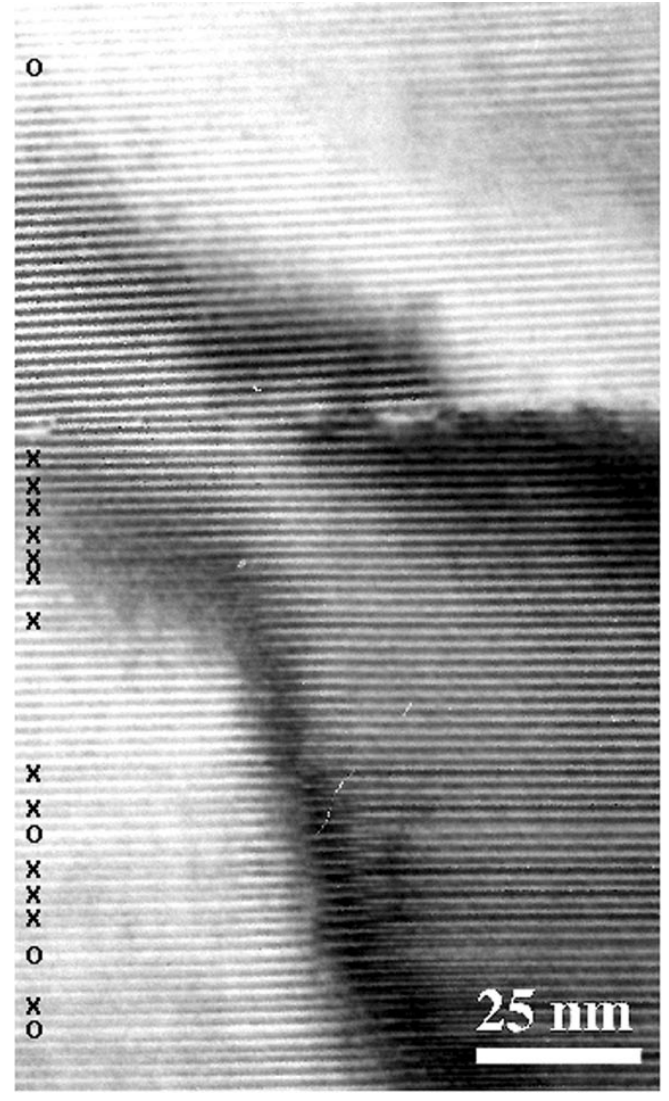

Fig. 4. TEM micrograph of some residual $\mathrm{Bi}-2212$ and $\mathrm{Bi}-2234$ structures within the Bi-2223 colonies in the interior of the conductor filaments of a wire with $J_{c}$ of $48 \mathrm{kA} / \mathrm{cm}^{2}(77 \mathrm{~K}, \mathrm{sf})$. $\mathbf{X}$ and $\mathbf{O}$ denote $\mathrm{Bi}-2212$ and $\mathrm{Bi}-2234$ intergrowths, respectively.

less than ten) could be found regularly in the Bi-2223 matrix. Fig. 4 shows a representative TEM micrograph of the latter region from a wire with $J_{c}$ of $19.8 \mathrm{kA} / \mathrm{cm}^{2}(77 \mathrm{~K}, 0.1 \mathrm{~T})$ and $48 \mathrm{kA} / \mathrm{cm}^{2}(77 \mathrm{~K}, \mathrm{sf})$. A wide range of intergrowth structures is present in the colony structure. Included are several single layers of the Bi-2234 phase. Some of the Bi-2212 intergrowth structures appear to be nearly periodic. While one may argue whether or not multiple $\mathrm{Bi}-2212$ intergrowths constitute a distinct grain or intergrowth structure, it is clear that Bi-2212 is a significant part of the microstructure; its reduction represents an important area for wire performance improvements. Unfortunately, it is difficult to obtain a quantitative estimation of total 2212 intergrowth concentration from TEM because of the very localized nature of the measurement.

While the new modifications for processing have been shown to reduce the $\mathrm{Bi}-2212$ phase and intergrowth density, it would be better to control this feature of the microstructure at the time of Bi-2223 formation. TEM analysis of samples quenched early in the process show a correlation between the density of intergrowths and the distance from the pools of liquid phase that supply the necessary components for precipitation of the liquid phase.

The micrograph in Fig. 5, obtained in a sample quenched from HT1 process, shows the precipitation of $\mathrm{Bi}-2223$ grains from a liquid phase. Note the high density of intergrowths in the $\mathrm{Bi}-2223$ grain which is furthest away from the amorphous phase.

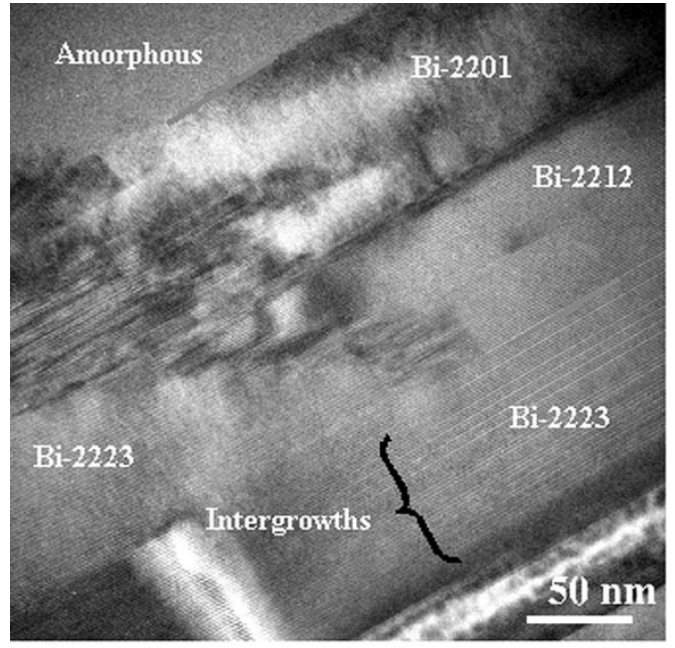

Fig. 5. TEM micrograph showing the liquid mediated growth of the Bi-2223 phase from $\mathrm{Bi}-2212 / \mathrm{Bi}-2201$ and the higher density of $\mathrm{Bi}-2212$ intergrowths in the Bi-2223 phase that is furthest from the pool of liquid. The sample was quenched during HT1 process.

In the case of earlier studies [8], [9], 2212 was observed at the basal plane boundaries of the 2223 grains and correlated with an $\sim 80 \mathrm{~K}$ kink in the $m$ vs $T$ curve of unrolled, as-produced samples. There was a highly nonlinear increase in $J_{c}$ as the 2212 intergrowth and the kink was eliminated. In contrast to tapes of that vintage whose maximum $J_{c}(77 \mathrm{~K}, 0 \mathrm{~T})$ values were $\sim 25 \mathrm{kA} / \mathrm{cm}^{2}$, the present higher performance samples have $m$ vs $T$ curves with only one sharp transition close to $105 \mathrm{~K}$ in the as-produced state. However, the $m$ vs $T$ results after rolling and the HRSEM images provide clear evidence that residual 2212 phase within the Bi-2223 colony is still a factor limiting supercurrent in very high performance Bi-2223 tape. Further work will focus on understanding the current limiting mechanism by the intergrowth and further eliminating 2212 intergrowth.

\section{CONCLUSION}

It was shown that residual $\mathrm{Bi}-2212$ is an important defect in MFC wires with regards to understanding current limiting mechanisms and improving the performance. A critical current density of $22.1 \mathrm{kA} / \mathrm{cm}^{2}$ at $77 \mathrm{~K}$ and $0.1 \mathrm{~T}(/ / \mathrm{c})$ has been measured for short samples, representing a new level of performance for Bi-2223 tape. A systematic microstructural study on the high performance tapes by SQUID magnetometry, transmission XRD, and TEM has identified many residual Bi-2212 intergrowths and a few $\mathrm{Bi}-2212$ grains within $\mathrm{Bi}-2223$ colonies as well as some other secondary phases. The relative amounts of residual Bi-2212 correlates with self-field $J_{c}$ across a range of experimental samples, suggesting that higher levels of performance will be achieved with further elimination of residual Bi-2212.

\section{ACKNOWLEDGMENT}

The authors thank DOE for its support of Wire Development Group and Dr. J. Jiang of the University of Wisconsin at Madison for helpful discussion. Work performed at the Argonne National Laboratory and the Los Alamos National Laboratory 
was sponsored by the U.S. Department of Energy (DOE), Energy Efficiency and Renewable Energy as part of a DOE program to develop electric power technology, and by the DOE Office of Science, Laboratory Technology Research Program.

\section{REFERENCES}

[1] L. Masur, J. Kellers, F. Li, S. Fleshler, and E. Podtburg, "Industrial high temperature superconductors: Perspectives and milestones," in MT-17, Geneva, Switzerland, Sept. 24-28, 2001.

[2] Y. B. Huang, X. Y. Cai, G. N. Riley, D. Larbalestier Jr, D. Yu, M. Teplitsky, A. Otto, S. Fleshler, and R. Parrela, "Progress in Bi-2223 wire performance," in Adv. Cryog. Eng. (Material), B. Balachandran, D. Gubser, and K. Hartwig, Eds., 2001, vol. 48B, pp. 717-723.

[3] K. Sandhage, G. N. Riley Jr, and W. L. Carter, "Critical issues in the OPIT processing of high- $J_{c}$ BSCCO superconductors," J. Metals, vol. 43, pp. 21-25, 1991.

[4] A. P. Malozemoff, W. Carter, S. Fleshler, L. Fritzemerier, Q. Li, L. Masur, P. Miles, D. Parker, R. Parrella, E. Podtburg, G. N. Riley Jr, M. Rupich, J. Scudiere, and W. Zhang, "HTS wire at commercial performance levels," IEEE Trans. Applied Superconductivity, vol. 9, pp. 2469-73, 1999
[5] V. A. Maroni, K. Venkataraman, A. J. Kropf, C. U. Segre, Y. B. Huang, and G. N. Riley Jr, "Nondestructive analysis of phase evolution and microstructyure development in $\mathrm{Ag} / \mathrm{BSCCO}$ composite superconductor by $25 \mathrm{keV}$ transmission X-ray diffraction," Physica C, to be published.

[6] S. Fleshler, Q. Li, R. Parrella, P. Walsh, W. Michels, G. N. Riley Jr, W. Carter, and B. Kunz, "Critical current densitys of high performance Bi-based superconducting composite wires in magnetic field," in Proc.of the 8th International Workshop on Critical Current in Superconductors, Singapore, 1996, pp. 81-86.

[7] L. Schwartzkopf, J. Jiang, X. Y. Cai, D. Apodaca, and D. C. Larbalestier, "The use of the in-field critical current density, $J_{c}(0.1 \mathrm{~T})$, as a better descriptor of BSCCO/Ag tape performance," Applied Physics Letters, vol. 75, pp. 3168-70, 1999

[8] A. Umezawa, Y. Feng, H. S. Edelman, Y. E. High, D. C. Larbalestier, Y. S. Sung, E. E. Hellstrom, and S. Fleshler, "Electronmagnetic granularity, critical current density, and low-Tc phase formation at grain boundaries in Bi2223 Ag sheathed tapes," Physica C, vol. 198, pp. 261-272, 1992.

[9] A. Umezawa, Y. Feng, H. S. Edelman, T. C. Willis, J. A. Parrell, D. C. Larbalestier, G. N. Riley Jr, and W. L. Carter, "Further evidence that the critical current density of Bi2223 Ag sheathed tapes is controlled by the residual layers of Bi2212 at (001) twist boundaries," Physica C, vol. 219, pp. 378-388, 1993. 